\title{
Anterior cruciate ligament and hamstrings: new research to guide clinical management
}

\author{
Nikos Malliaropoulos, ${ }^{1-3}$ Xavier Valle, ${ }^{4,5}$ Gil Rodas, ${ }^{5}$ Luis Til ${ }^{5}$
}

Soft tissue injuries still generate much research on the diagnosis, treatment and prevention. Outcomes from research help clinicians with their decisions, however, there always remains more to know.

\section{BETTER UNDERSTANDING OF ANTERIOR CRUCIATE LIGAMENT INJURIES}

Genetic variants within genes involved in fibrillogenesis have previously been implicated in anterior cruciate ligament (ACL) injury susceptibility. Proteoglycans also have important functions in fibrillogenesis and maintaining the structural integrity of ligaments. These independent associations and haplotype analyses suggest that regions that encode for proteoglycans may modulate the ligament fibril properties and may be associated with susceptibility to ACL injury (see page 1640). Sustaining an ACL injury and having surgical repair results in a relatively low rate of return to competitive sport despite the high rates of success in terms of knee impairment outcomes. Other factors may be contributing to low return-to-sport outcomes and it is worth considering psychological factors (see page 1613).

\section{HAMSTRING RESEARCH THAT GUIDES CLINICAL INTERVENTION}

Are biceps femoris and semitendinosus teammates or competitors? The vulnerability of the hamstring muscles to footballrelated injury is possibly related to the complexity and coherence in the synergistic muscle recruitment of the biceps femoris and the semitendinosus. Despite their interrelated morphology and similar response to heavy eccentric loading, there are slight differences in their coordination and activity, with the biceps femoris compensating for the lack of endurance capacity of the semitendinosus (see page 1599). Hamstring injury requires a

\footnotetext{
${ }^{1}$ Sports Clinic, Mile End Hospital Barts and The London, UK; ${ }^{2}$ National Athletics Clinic, Thessaloniki, Greece; ${ }^{3}$ Center Sports and Exercise Medicine QMUL, London, UK; ${ }^{4}$ Anatomy Department, Professional School of Sports Medicine, University of Barcelona, Spain; ${ }^{5}$ Medical Services, FC Barcelona, Barcelona, Spain
}

Correspondence to Dr Nikos Malliaropoulos; contact@sportsmed.gr patient-rated outcome measure that quantitatively measures the severity and the impact of symptoms on function and sports ability in patients with acute hamstring injuries (see page 1607).

\section{TENDONS AND FASCIA CONTRIBUTE TO THE BURDEN OF SOFT TISSUE INJURIES}

Glucocorticoid injection into the subacromial bursa results in histological and immunohistochemical changes to tendon that involves the excitatory glutaminergic system. The most notable response was the increase in the glutamate receptor NMDAR1. These novel in vivo findings add weight to the recent evidence demonstrating that glucocorticoid may have harmful effects on tendon (see page 1620).

Deep posterior chronic exertional compartment syndrome (dp-CECS) of the lower leg is a common cause of exercise-related pain in young endurance athletes. The quality of studies that investigated dp-CECS is poor and prospective, controlled or randomised studies are required. As outcomes of current management regimes are disappointing, studies of $\mathrm{dp}$-CECS should focus on optimising diagnostic criteria and standardisation of treatment modalities (see page 1592).

\section{MAINTAINING HEALTH IN SOFT TISSUES WITH EXERCISE}

Finally, this BJSM issue also includes a 2014 update of the global health Initiative for Exercise is Medicine. Broad implementation of evidence-based strategies for physical activity promotion via counselling and referral systems in clinical practice has the potential to help reduce population inactivity rates and related non-communicative diseases morbidity and mortality. The Exercise is Medicine global health initiative can accelerate the integration of physical activity promotion in healthcare settings by aiding the establishment of infrastructure including policy, surveillance, training and research activities in this area (see page 1627).

\section{PUT BARCELONA, 7-9 OCTOBER 2015 IN YOUR CALENDAR!}

One of the main European sports and exercise medicine physicians events is the ECOSEP congress. This biannual, international, interdisciplinary event attracts participants from all over Europe. It is dedicated to sports medicine physicians, orthopaedic surgeons, general practitioners, physiotherapists, podiatrists, podiatric surgeons, sports scientists, academics, researchers and representatives from many contributing medical organisations.

Its legacy is established, from 2008 in Thessaloniki; 2010 in London; to 2013 in Frankfurt. The 4th ECOSEP congress will be in autumn in 2015 in Barcelona, organised by FC Barcelona medical department simultaneously with the 7 th MuscleTech network. During the conference there will be three objectives: an interesting and high-quality scientific programme, to progress sports and exercise medicine in Europe, and of course, improve the participants' knowledge, as well as a pleasant experience of the city. Both organisations, ECOSEP and FC Barcelona, share the view that sports physicians and sport and exercise medicine have an important role in athlete's health, education and performance. The sport physicians in FCB medical department work with other sports medicine practitioners to coordinate the activities of health and performance professionals working in the club. FC Barcelona, a FIFA medical centre of excellence, and ECOSEP work to elevate sports and exercise medicine standards, encouraging its members to collaborate in athlete management and research. The 4th ECOSEP congress and the 7th MuscleTech network will offer an interesting and attractive program, and the people involved in the congress organisation, the city and our gastronomy will come together in a great sports and exercise medicine event.

Enjoy this ECOSEP-shaped BJSM. If you are a sports physician in Europe you can access BJSM through the ECOSEP members' website. Get BJSM updates via the popular blog (http://blogs.bmj.com./ bjsm) and be among the over 300000 listeners to BJSM podcasts (http://podcasts. bmj.com/bjsm). BJSM is also easy to follow via Twitter (@BJSM_BMJ).

\section{Competing interests None.}

Provenance and peer review Not commissioned; internally peer reviewed.

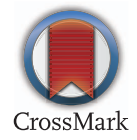

To cite Malliaropoulos $\mathrm{N}$, Valle $\mathrm{X}$, Rodas $\mathrm{G}$, et al. $\mathrm{Br}$ J Sports Med 2014;48:1583.

Accepted 14 October 2014

Br J Sports Med 2014;48:1583.

doi:10.1136/bjsports-2014-094326 